\title{
Proceedings
}

\section{Neural States in Tourism Travel Videos ${ }^{\dagger}$}

\author{
Pablo Ruiz ${ }^{1, *}$, Raquel Tinoco-Egas ${ }^{2}$ and Carlos Cevallos ${ }^{1,3}$ \\ 1 Departamento de Ingeniería Mecánica, Escuela Politécnica Nacional, Quito 170525, Ecuador; \\ ccevallo@ulb.ac.be \\ 2 Facultad de Ciencias Empresariales, Universidad Técnica de Machala, Machala 70212, Ecuador; \\ rmtinoco@utmachala.edu.ec \\ 3 Neuropsychology and Functional Neuroimaging Research Unit, Center for Research in Cognition and \\ Neurosciences, Université Libre de Bruxelles, 1050 Brussels, Belgium \\ * Correspondence: pablo.ruiz01@epn.edu.ec \\ + Presented at the 1st International Electronic Conference on Brain Sciences, 10-25 November 2020; \\ Available online: https://iecbs.sciforum.net/.
}

Citation: Ruiz, P.; Tinoco-Egas, R.; Cevallos, C. Neural States in Tourism Travel Videos. Proceedings 2021, 71, 6. https://doi.org/10.3390/ IECBS-08465

Published: 18 November 2020

Publisher's Note: MDPI stays neutral with regard to jurisdictional claims in published maps and institutional affiliations.

Copyright: $\odot 2020$ by the authors. Licensee MDPI, Basel, Switzerland. This article is an open access article distributed under the terms and conditions of the Creative Commons Attribution (CC BY) license (http://creativecommons.org/licenses/by/4.0/).

\begin{abstract}
In marketing, there are many methods to relate reactions to products to customer preference. Current electroencephalography (EEG) signal analysis in the neuromarketing field focuses mainly on correlations between selected electrodes and hemisphere-based analysis on single scalp measures. The present study shows microstate analysis of brain EEG signals in goal-oriented videos. We measured a 16 channel EEG with an Emotiv EPOC+ device. We used two oriented videos from the Ecuadorian Government to publicize Ecuador as a tourist destination. We used a Topographic Atomize and Agglomerate Hierarchical Clustering (TAAHC) microstate analysis for the duration of the EEG as the participants watched each video. We picked the four predominant, in total time and repeatability, microstate maps that represent more than $50 \%$ of the entire recording time. We also show, in time, how topographies are represented along the video, which in a later step could be correlated with the images observed in the videos. We show the existing relations between the existing microstates. A microstate analysis of brain signal behavior across time might be a valid methodology and useful tool to analyze videos with marketing purposes.
\end{abstract}

Keywords: microstate; EEG; neuromarketing; video; Emotiv

\section{Introduction}

There are a variety of emerging methods that the tourism industry uses to advertise [1]: Near Field Communication (NFC) posters [2], advertising in web platforms [3,4], videos $[5,6]$ and video games $[7,8]$. These methods mainly make use of audiovisual media to be attractive [9-11]. There is a neural measurable response from the user based on visual information $[12,13]$. One of the most used methods to gather consumer opinions is to conduct surveys or questionnaires based on the advertising object [14] as well as institute psychophysiological measures [15-18]. EEG analysis helps in the analysis of consumer behavior [19] that could predict the advertising preference of the customer and gain insights from brain behavior [3-7,20]. Another way to analyze EEG signals is to recognize the main undergoing process using topographical stability analysis; this process is called Microstate [21]. This method has been proven to aid in understanding disorders such as resting-state and neuropsychiatric diseases [22-25].

The aim of this work is to show how new methodologies can aid in the exploration of brain scalp topographies from tourist videos using a portable EEG device. The results may provide information which focuses on key details found in the audiovisual stimuli, presented as videos. This study provides knowledge about the sequences of the microstates and their relationship with visual data within tourist videos. 


\section{Materials and Methods}

One healthy male participated as a volunteer in the present methodological study. The participant did not have any history of psychiatric or neurological disease; also, he did not take medication that could influence the results of the experiment. The subject was instructed to watch the two tourist videos of Ecuador made publicly available in social media.

EEG data was recorded using an Emotiv EPOC+ device with 16-electrodes (2 reference electrodes) distributed according to international 10-20 location. Data was recorded from the EEG device at $2048 \mathrm{~Hz}$ and hardware down sampled to $128 \mathrm{~Hz}$, with a bandwidth of $0.2-45 \mathrm{~Hz}$ referenced to the mastoids. EEG signals were captured simultaneously when the user was watching the videos. We removed muscle activity and eye artifacts, with a 1 $\mathrm{Hz}$ high-pass filter and independent component analysis (ICA) through EEGLAB Matlab [26] toolbox in both videos. We used microstates segmentation to analyze EEG signals with Cartool software, which works through 2 clustering methods, K-Means and Topographic AAHC [27]. K-Means is a partitioning method in which the user is required to specify the number of microstate classes [28], while TAAHC belongs is a form of hierarchical clustering which starts with all EEG samples, then removes the worst clusters [29] and selects the best clustering sequence. After EEG segmentation, we correlated the most representative microstates with the most representative images from the videos. Finally, to represent relations to each microstate in the sequence, we used the software Circos which can represent the size, connections and relations between microstates [30].

\section{Results}

\subsection{EEG Microstates Segmentation}

There are 19 and 23 scalp topographies, for the first and second video, respectively. The most representative maps were elected according to cumulative time and repetitions in the records; there were four maps, which represent $73.74 \%$ for the first video and $64.69 \%$ for the second video (Figure 1). A video consists of a set of images which represent the video. We chose one image for each microstate of the videos and observed the most repetitive object of each image as illustrated in Figure 2. For video 1 we observed mostly sky in MS8-V1, mountains in MS9-V1, water in MS10-V1 and people in MS13-V1. In the case of video 2 we observed mostly sky in MS12-V2, edifications in MS15-V2, water in MS16-V2 and people in MS18-V2.
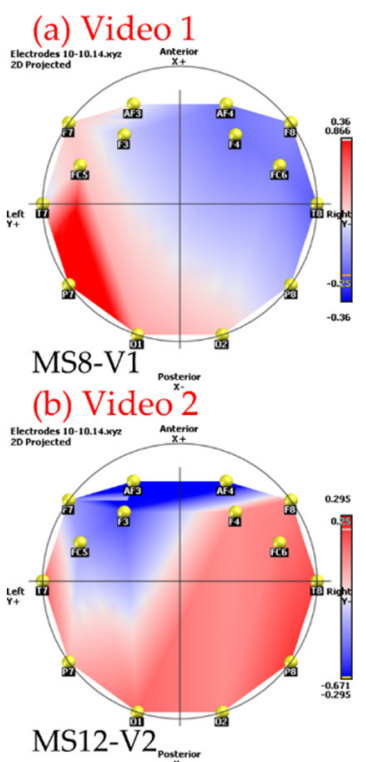
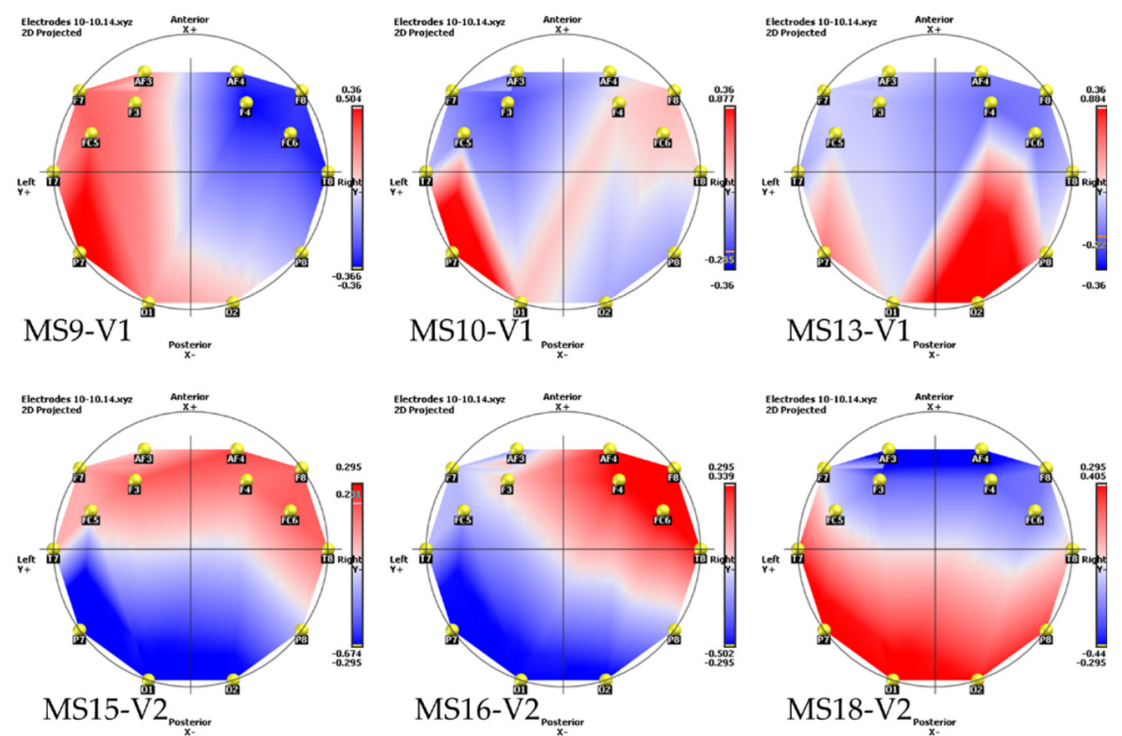

Figure 1. EEG microstate maps by the signals captured with Emotiv EPOC+ device: (a) The first panel includes the most representative maps in video 1 according to the number of repetitions and the time present: MS8-V1, MS9-V1, MS10-V1, MS13-V1; (b) The second panel includes the most representative maps in video 2 according to the number of repetitions and the time present: MS12-V2, MS15-V2, MS16-V2, MS18-V2. 
(a) Video 1

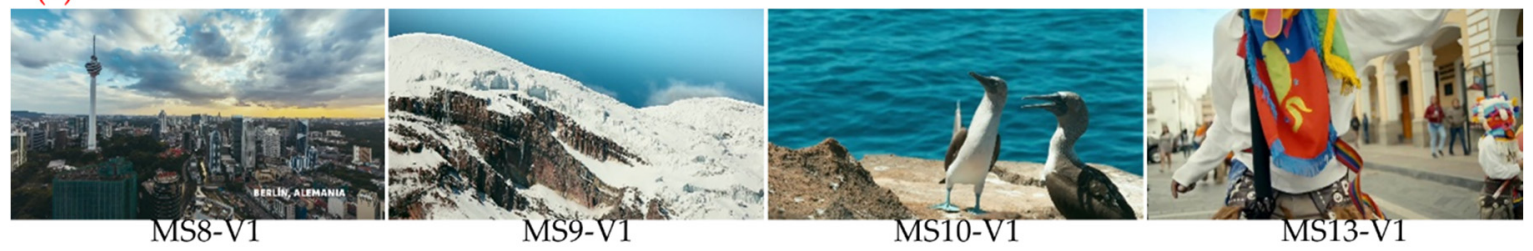

(b) Video 2

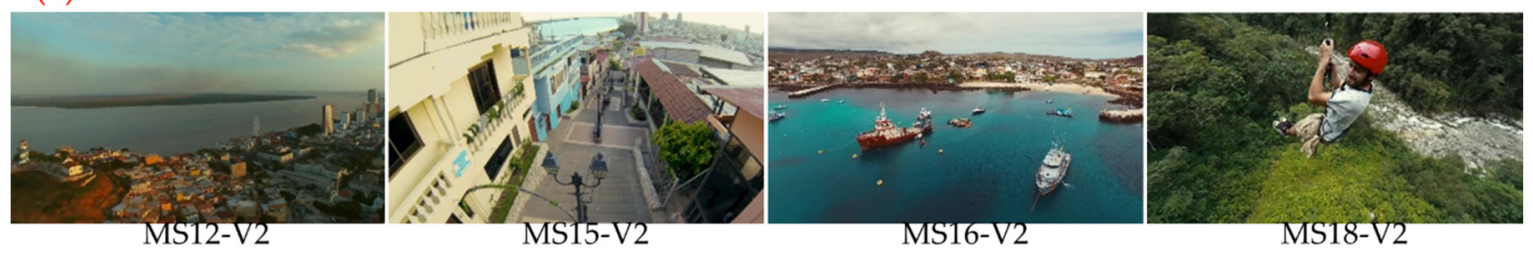

Figure 2. Images of tourist videos extracted as frames: (a) The first panel includes the most representative images of each principal topography in Video S1; (b) The second panel includes the most representative images of each principal topography in Video S2.

\subsection{Relation between Microstates}

To show how the microstates are related to each other, we observed the sequences and used the Circos software to illustrate and map a network of sequences for each microstate of the two videos (see Figures A1 and A2). We can also observe how much time is occupied by the most predominant topographies illustrated in Figure 1 and their relations with the others. The width of each band between both topographies represents the time elapsed until the sequence continues and the weight (number of repetitions) for this sequence.

\section{Discussion}

Microstate analysis studies brain states in a functional manner [31]. These "atoms of thought" may indicate the relationships between presented images from goal-oriented videos to undergoing neural processes. This methodology suggests that due to the high duration time of each predominant microstate (four per each video), these can be represented by the most repetitive figure finding in the same video. However, these images were not always coincident with this microstate, which suggests that this kind of behavior, represented by microstates and their high duration time, could be due to the participant's emotions and interest in the video, described by Becker H. et al. in their study [32].

The study presented here provides the necessary information on how to develop research focused on finding principal brain activitiy and their stable times to establish relations between microstates and images captured in videos. This representation of relationships in Circos is a great opportunity to observe widely how many microstates exist when someone watches videos or performs daily activities. On the other side, to complement this study, it is necessary to discover participant opinion using questionnaires or surveys which will allow the researcher to show the relationship between emotions, images, and microstates.

Supplementary Materials: The following are available online at https://www.youtube.com/ watch? $\mathrm{v}=\mathrm{Rm}-\mathrm{ZA7eTW8s,} \mathrm{Video} \mathrm{S1:} \mathrm{Ecuador} \mathrm{tu} \mathrm{lugar} \mathrm{en} \mathrm{el} \mathrm{mundo} \mathrm{(Ecuador} \mathrm{a} \mathrm{tu} \mathrm{manera);}$ https://www.youtube.com/watch?v=Tw1bBmdA3ew, Video S2: Ecuador tu lugar en el mundo (Ecuador a tu aire).

Institutional Review Board Statement: The study was conducted according to the guidelines of the Declaration of Helsinki, and approved (exempted) by the Institutional Review Board of Claremont Graduate University (protocol code: 3122 approved april the 2nd 2018). 
Informed Consent Statement: Informed consent was obtained from all subjects involved in the study

Data Availability Statement: All data is publicly available https://oi.org/10.6084/m9.figshare. 13140395, https://doi.org/10.6084/m9.figshare.13140383.

Acknowledgments: The authors would like to thank Paul J. Zak from Claremont Graduate University for supporting the project and Jennifer Borja for secretarial assistance. This work was funded by Universidad Técnica de Machala (Ecuador), Université Libre de Bruxelles (Belgium) and Escuela Politécnica Nacional (Ecuador).

Conflicts of Interest: The authors declare no conflict of interest.

\section{Appendix A}

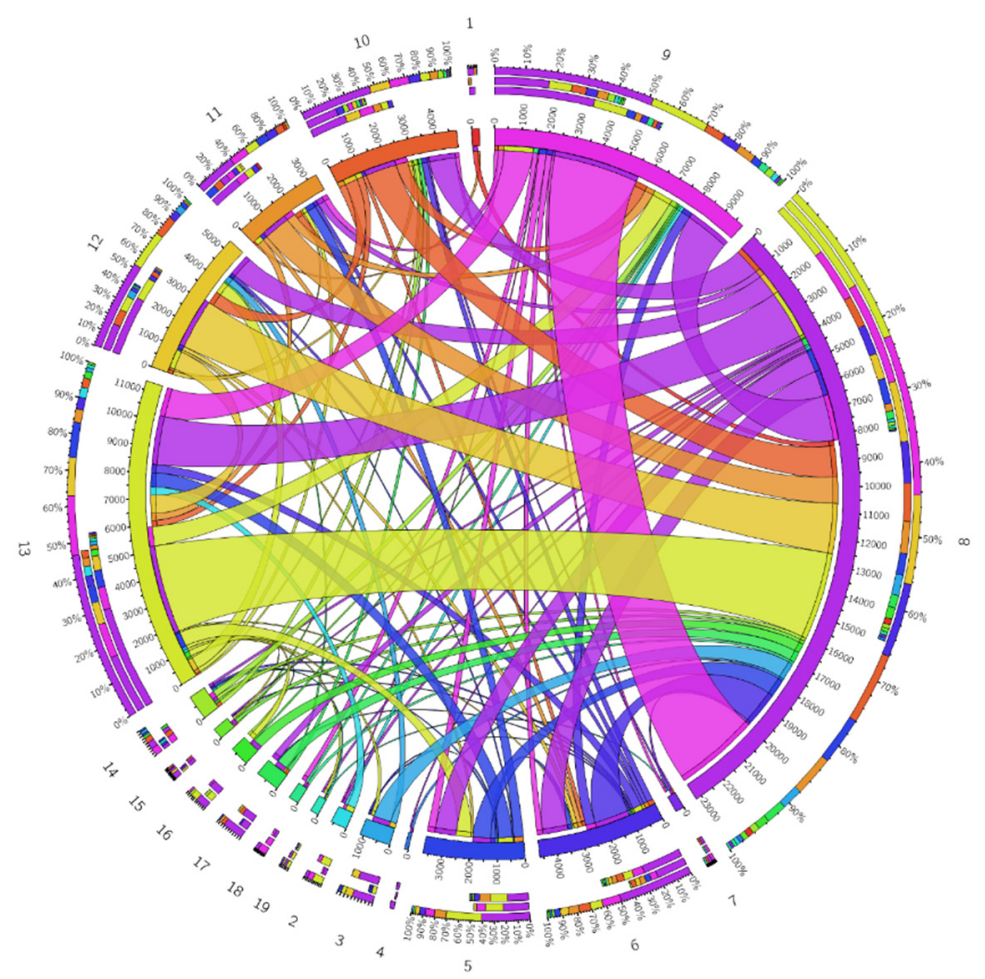

Figure A1. Relation between microstates of video 1. The figure shows each relation between microstates, their time lapse in the record and how many relations exist. 


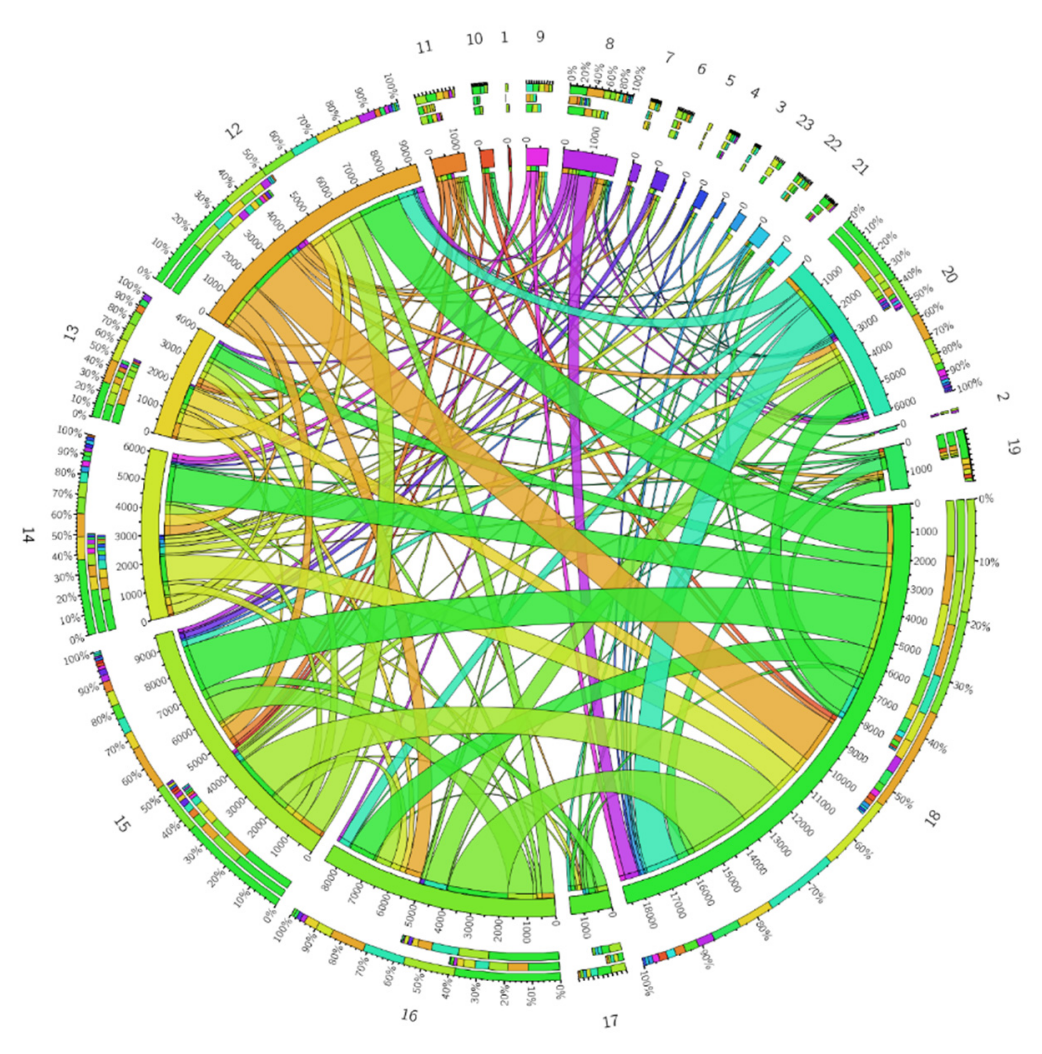

Figure A2. Relation between microstates of video 2. The figure shows each relation between microstates, their time lapse in the record and how many relations exist.

\section{References}

1. Stankov, U.; Gretzel, U. Tourism 4.0 technologies and tourist experiences: A human-centered design perspective. Inf. Technol. Tour. 2020, 22, 477-488, doi:10.1007/s40558-020-00186-y.

2. Naraparaju, S.; Jalapati, P.; Nara, K. Smart poster for tourism promotion through NFC technology. In Studies in Computational Intelligence; Springer: Berlin, Germany, 2019; Volume 771, pp. 507-519.

3. Reino, S.; Hay, B. The Use of YouTube as a Tourism Marketing Tool. In Proceedings of the 42nd Annual Travel \& Tourism Research Association Conference, London, ON, Canada, 19-21 June 2011.

4. Fatanti, M.N.; Suyadnya, I.W. Beyond User Gaze: How Instagram Creates Tourism Destination Brand? Procedia-Soc. Behav. Sci. 2015, 211, 1089-1095, doi:10.1016/j.sbspro.2015.11.145.

5. Shani, A.; Chen, P.-J.; Wang, Y.; Hua, N. Testing the impact of a promotional video on destination image change: Application of China as a tourism destination. Int. J. Tour. Res. 2010, 12, 116-133, doi:10.1002/jtr.738.

6. Stankov, U.; Kennell, J.; Morrison, A.M.; Vujičić, M.D. The view from above: The relevance of shared aerial drone videos for destination marketing. J. Travel Tour. Mark. 2019, 36, 808-822, doi:10.1080/10548408.2019.1575787.

7. Cipolla-Ficarra, F.V.; Cipolla-Ficarra, M.; Harder, T. Realism and cultural layout in tourism and video games multimedia systems. In Proceedings of the 2008 ACM International Conference on Multimedia, with Co-Located Symposium and Workshops (MM'08), Vancouver, BC, Canada, 27-31 October 2008; 2008, pp. 15-22.

8. Dubois, L.-E.; Gibbs, C. Video game-induced tourism: A new frontier for destination marketers. Tour. Rev. 2018, 73, 186-198, doi:10.1108/tr-07-2017-0115.

9. O'Brien, M. The audiovisual action plan: A new audiovisual policy for Ireland. Cult. Trends 2019, 28, 417-428, doi:10.1080/09548963.2019.1681670.

10. Liestøl, G.; Ritter, C.S.; Ibrus, I. Audiovisual Industries and Tourism: Forms of Convergence. In Emergence of Cross-Innovation Systems; Emerald Publishing Limited: Bingley, UK, 2019; pp. 165-172.

11. Di Cesare, F.; La Salandra, A.A.; Craparotta, E. Films and Audiovisual Potentiality in Tourism Destination Promotion: A European Perspective. Tour. Rev. Int. 2020, 16, 101-111.

12. Ecebolla, A.-M.; Epetieau, M.; Ecevallos, C.; Eleroy, A.; Edan, B.; Echeron, G. Long-Lasting Cortical Reorganization as the Result of Motor Imagery of Throwing a Ball in a Virtual Tennis Court. Front. Psychol. 2015, 6, 1869, doi:10.3389/fpsyg.2015.01869.

13. Leroy, A.; Cevallos, C.; Cebolla, A.-M.; Caharel, S.; Dan, B.; Echeron, G. Short-term EEG dynamics and neural generators evoked by navigational images. PLOS ONE 2017, 12, e0178817, doi:10.1371/journal.pone.0178817.

14. Alamäki, A.; Pesonen, J.; Dirin, A. Triggering effects of mobile video marketing in nature tourism: Media richness perspective. Inf. Process. Manag. 2019, 56, 756-770, doi:10.1016/j.ipm.2019.01.003. 
15. Alejandro, V. Generación de emociones en la intención de compra. Rev. Ciencias Soc. 2019, 3, $218-229$.

16. Li, S.; Walters, G.; Packer, J.; Scott, N. Using skin conductance and facial electromyography to measure emotional responses to tourism advertising. Curr. Issues Tour. 2016, 21, 1761-1783, doi:10.1080/13683500.2016.1223023.

17. Hadinejad, A.; Moyle, B.D.; Scott, N.; Kralj, A. Emotional responses to tourism advertisements: The application of FaceReader ${ }^{\mathrm{TM}}$. Tour. Recreat. Res. 2018, 44, 131-135, doi:10.1080/02508281.2018.1505228.

18. Beck, J.; Egger, R. Emotionalise Me: Self-reporting and Arousal Measurements in Virtual Tourism Environments. In Information and Communication Technologies in Tourism 2018; Springer: Basel, Switzerland, 2018; pp. 3-15.

19. Tinoco-Egas, R. Fundamentos del neuromarketing desde la neurociencia del consumidor para la generación de confianza. Redmarka Rev. Mark. Appl. 1970, 1, 29-40, doi:10.17979/redma.2016.01.016.4870.

20. Hsu, L.; Chen, Y.-J. Neuromarketing, subliminal advertising, and hotel selection: An EEG study. Australas. Mark. J. (AMJ) 2020, doi:10.1016/j.ausmj.2020.04.009.

21. Koenig, T.; Lehmann, D. Microstates in Language-Related Brain Potential Maps Show Noun-Verb Differences. Brain Lang. 1996, 53, 169-182, doi:10.1006/brln.1996.0043.

22. Damborská, A.; Tomescu, M.I.; Honzírková, E.; Barteček, R.; Hořínková, J.; Fedorová, S.; Ondruš, Š.; Michel, C.M. EEG RestingState Large-Scale Brain Network Dynamics Are Related to Depressive Symptoms. Front. Psychiatry 2019, 10, 548, doi:10.3389/fpsyt.2019.00548.

23. Michel, C.M.; Koenig, T. EEG microstates as a tool for studying the temporal dynamics of whole-brain neuronal networks: A review. NeuroImage 2018, 180, 577-593, doi:10.1016/j.neuroimage.2017.11.062.

24. D'Croz-Baron, D.F.; Baker, M.; Michel, C.M.; Karp, T. EEG Microstates Analysis in Young Adults With Autism Spectrum Disorder During Resting-State. Front. Hum. Neurosci. 2019, 13, 173, doi:10.3389/fnhum.2019.00173.

25. Murray, M.M.; Brunet, D.; Michel, C.M. Topographic ERP Analyses: A Step-by-Step Tutorial Review. Brain Topogr. 2008, 20, 249-264, doi:10.1007/s10548-008-0054-5.

26. Delorme, A.; Makeig, S. EEGLAB: An open source toolbox for analysis of single-trial EEG dynamics including independent component analysis. J. Neurosci. Methods 2004, 134, 9-21, doi:10.1016/j.jneumeth.2003.10.009.

27. Brunet, D.; Murray, M.M.; Michel, C.M. Spatiotemporal Analysis of Multichannel EEG: CARTOOL. Comput. Intell. Neurosci. 2011, 2011, 1-15, doi:10.1155/2011/813870.

28. Lloyd, S. Least squares quantization in PCM. IEEE Trans. Inf. Theory 1982, 28, 129-137, doi:10.1109/tit.1982.1056489.

29. Poulsen, A.T.; Pedroni, A.; Langer, N.; Hansen, L.K. Microstate EEGlab toolbox: An introductory guide. bioRxiv 2018, doi:10.1101/289850.

30. Krzywinski, M.; Schein, J.; Birol, I.; Connors, J.; Gascoyne, R.; Horsman, D.; Jones, S.J.; Marra, M.A. Circos: An information aesthetic for comparative genomics. Genome Res. 2009, 19, 1639-1645, doi:10.1101/gr.092759.109.

31. Lehmann, D.; Pascual-Marqui, R.D.; Michel, C. EEG microstates. Scholarpedia 2009, 4, 7632, doi:10.4249/scholarpedia.7632.

32. Becker, H.; Fleureau, J.; Guillotel, P.; Wendling, F.; Merlet, I.; Albera, L. Emotion Recognition Based on High-Resolution EEG Recordings and Reconstructed Brain Sources. IEEE Trans. Affect. Comput. 2017, 11, 244-257, doi:10.1109/taffc.2017.2768030. 